\title{
CONJUNTO DE CONCEITOS RELACIONADOS AO LUGAR EM GEOGRAFIA HUMANISTA: UMA ABORDAGEM PARA COMPREENDER A RELAÇÃO AFETIVA DOS HOMENS COM O MEIO AMBIENTE \\ SET OF CONCEPTS RELATED TO THE PLACE IN HUMANIST GEOGRAPHY: AN APPROACH TO UNDERSTAND THE AFFECTIVE RELATIONSHIP OF MEN WITH THE ENVIRONMENT
}

\author{
Rodrigo Capelle Suess ${ }^{1}$ \\ ${ }^{1}$ Secretaria de Estado de Educação do Distrito Federal (SEEDF), Brasília, DF, Brasil \\ Correspondência para: Rodrigo Capelle Suess (rodrigo.capellesuess@gmail.com) \\ doi: 10.12957/geouerj.2018.30883 \\ Recebido em: 21 out. 2017 | Aceito em: 22 ago. 2018
}

\section{SCREENED BY $\checkmark$ iThenticate}

\section{RESUMO}

O lugar é um conceito-chave em Geografia, sua definição nem sempre foi clara ao longo da história dessa ciência. O mesmo parece tomar contornos mais evidentes e ocupar o seu devido local com a Geografia Humanista, a partir da década de 1970. Contudo, ainda se faz necessário reforçar as concepções teóricas que cercam esse conceito. Nesse aspecto, o desafio deste trabalho é identificar e analisar um conjunto de conceitos relacionados ao lugar em Geografia humanista que permita compreender a relação afetiva das pessoas com o meio ambiente. Sendo assim, são elencados os conceitos de cultura, símbolo, significado, grupos sociais, mundo vivido, cotidiano, experiência, corpo, casa e lar. Assim, o lugar, enquanto centro de significados e valores, ao lado desses conceitos, se torna uma importante ferramenta para uma leitura significativa das relações de acordos e desavenças do ser humano com o seu universo vivido.

Palavras-chave: Lugar; Geografia Humanista; Mundo vivido; Significados; Conceitos geográficos.

\begin{abstract}
The place is a key-concept in Geography, its definition has not always been clear throughout history this science. The same seems to take on more evident contours and occupy its due place with the Humanist Geography, from the 1970s. However, still it is necessary to reinforce the concepts theories surrounding this concept. In this aspect, this work is to identify and analyze a set of concepts related to the place in Humanist Geography that allows to understand the affective relationship of people with the environment. Therefore, are listed the concepts of culture, symbol, meaning, Social groups, living world, everyday life, experience, body, house and home. Thus, the place, as center of meanings and values, Next to these concepts, becomes an important tool for meaningful reading the relations of agreements and disagreements of the human being with his lived universe.
\end{abstract}

Keywords: Place; Humanist Geography; lived world; Meanings; Geographical concepts.

\section{INTRODUÇÃO}

Devemos notar que a geografia brasileira, nas últimas décadas, passou a se dedicar ao estudo do mundo vivido e do lugar em trabalhos desenvolvidos por Mello (1991; 2000), Holzer (1992) e Marandola (2008) e seus orientandos. Grupos de pesquisas surgiram com a preocupação de mapear o sentimento e o entendimento dos indivíduos e grupos sociais com respeito aos lugares dos homens. 
Lugar é a palavra chave da perspectiva humanista em geografia, advindo da concepção fenomenológica do universo vivido, um todo indissociável composto pela pessoa, a ambiência, amigos, parentes, turistas, "canções que minha mãe me ensinou" (SCHUTZ, 1979) e toda sorte de elementos que permite a pessoa sentir-se em casa. Lugar, portanto, se confunde com o lar por ser dotado de afeição, intimidade, desenvoltura, experiência, como apontaram em suas obras Tuan (2013) e os autores acima citados.

De modo geral, como expõe Tuan (2011), o lugar na concepção geográfica humanista se delineia como um espaço dotado de significado para indivíduos ou grupos sociais. Dessa forma, esse conceito, constitui-se na melhor forma geográfica de conhecer os valores, significados e os sentimentos construídos pelo homem no espaço.

A Geografia dispõe de ferramentas para fazer leitura de seu principal objeto de estudo, qual seja, o espaço geográfico. Do modo que construir uma casa demanda diversos instrumentos, o saber geográfico, também, necessita deles para erguer teorias e conceitos. Sendo assim, como veremos pela frente, todo conceito é uma ordenação lógica, generalização e, por consequência, envolve um conjunto de outros conceitos, buscou-se selecionar alguns deles que são fundamentais para construção do conceito de lugar em uma perspectiva humanista. O lugar, neste sentido, surge como um recurso para analisar os artefatos em suas dimensões simbólicas e culturais, por meio de relatos verbais da música, da literatura e outros enfoques a partir dos indivíduos e grupos sociais.

Podemos destacar conceitos como cultura, grupos sociais, corpo, mundo vivido, cotidiano, experiência, lar, casa, símbolo, significado. Esses conceitos contribuem para uma leitura do lugar que permite identificar a relação afetiva das pessoas com o meio ambiente. Assim, esse trabalho tem como objetivo discutir e conhecer a respeito desses conceitos, pois acreditamos que eles são fundamentais para a compreensão do lugar na Geografia Humanista. Essa reflexão se justifica devido a pouca importância dada ao conceito de lugar na Geografia, apesar do avanço, principalmente, nas últimas décadas. 
Trata-se de uma pesquisa reflexiva e propositiva que utilizou como base a pesquisa bibliográfica e a pesquisa intuitiva. Dessa forma, esse trabalho se constitui como importante material teórico para pensar o conceito de lugar.

\section{CONCEITOS}

Poderíamos suprimir aqui esse tópico, que passaria despercebido pela maioria de nós, ao consultar diversas obras da Geografia, inclusive as que falam de conceitos, sequer mencionam o que se trata essa palavra e o que ela significa, o mesmo acontece se formos procurar por categoria. Nesse trabalho procurou dar um pouco mais de importância a essas questões.

Segundo Japiassu \& Marcondes (2001, p. 39) "conceito (lat. concepturn: pensamento, idéia). Em seu sentido geral, é uma noção abstrata ou idéia geral". Daí, percebemos que a formação dos conceitos está totalmente vinculada com o nosso pensar, com a nossa capacidade de abstrair e de construir uma idéia, ele é antes de tudo, uma construção social da mente (VIGOTSKI, 1989).

Japiassu \& Marcondes (2001, p. 39) discuti a idéia de conceito "enquanto idéia abstrata construída pelo espírito". Sendo assim, ele tem como elementos de sua construção: "a) a compreensão ou o conjunto dos caracteres que constituem a definição do conceito (o homem: animal. mamífero, bípede etc.). b) a extensão ou o conjunto dos elementos particulares dos seres aos quais se estende esse conceito".

Em termos gerais, segundo Sposito (2004), pode se dizer que todo conceito contém sua história, e por isso devemos identificar os autores, as tendências, as pessoas ou grupos ao longo do tempo e do espaço que fazem parte do seu enredo, isso também indica sua abertura para o futuro, em vistas das mudanças de pensamentos decorrentes das transformações na sociedade. Sempre que evocado, o conceito exige outros conceitos para efeitos de comparação ou superação (SPOSITO, 2004). Ainda, segundo Santos (2004, p. 147) "as categorias sob ângulos puramente nominal mudam de significação com a história, 
mas elas também constituem uma base permanente e, por isso mesmo, um guia permanente para a teorização".

A partir de Vigotski (2008) entendemos que a formação de conceitos é um processo criativo e complexo, que envolve diversas funções intelectuais para essa formulação, no qual a palavra media todas essas operações. A generalização é acompanhada pela síntese e pela constituição de um sistema, de uma imagem sincrética por meio do pensamento por complexos e o domínio da capacidade de abstrair, nasce o conceito, quanto mais abstrato e sistematizado, mais próximo da sua versão científica, o enfraquecimento desses níveis o aproxima de sua versão espontânea, o que diferencia um do outro é o nível de experiência, apesar de seguirem processos de formação muitas vezes díspares, um depende do outro em uma relação concreta-abstrata. Um conceito existe para resolver um problema, o seu significado é mutável assim como as pessoas são.

De acordo com Sposito (2004) os conceitos e as idéias fazem parte da elaboração teórica do conhecimento científico em Geografia. Partimos do pressuposto que todo conceito é uma ordenação lógica, generalização e por consequência um conjunto de outros conceitos. Desse modo, buscamos selecionar alguns desses outros conceitos que são fundamentais para construção do conceito de lugar.

\section{Cultura}

Certamente, a cultura imprime valores e costumes que interferem nas relações que o homem estabelece com o espaço e com outros indivíduos. Nas palavras de Buttimer (1985, p. 228) o "lugar é o somatório das dimensões simbólicas, emocionais, culturais, políticas e biológicas”. Entendemos que estudar o lugar, assim como outro estudo que foca o ser humano, é estudar a cultura. Desconsiderar essa abordagem é um grande erro.

Como decorre Berdoulay (2012), o termo cultura tem múltiplos sentidos, que podem ser refletido em dois eixos: o da cultura como reunião de traços que caracterizam uma sociedade particular; e o da 
cultura como fenômeno individual, como desenvolvimento pessoal do indivíduo em seu contexto. Por conseguinte, esse conceito assume a complexidade tanto com o coletivo quanto com o particular.

A cultura para a versão clássica da Geografia Cultural é definida em termos amplos, agregando, principalmente, as manifestações naturais, mas também não deixa de englobar os costumes, crenças, hábitos, habilidades, técnicas, leis, artes, linguagem e entre outros. Compreendida como uma entidade supraorgânica, pairando sobre a sociedade e determinando suas ações (CORRÊEA e ROSENDAHL, 2011). Essa idéia de cultura como entidade supraorgânica foi formulada pelos antropólogos Alfred Kroeber e Robert Lowie na primeira parte da metade do século XX. Assim, a noção de cultura como uma entidade acima do homem, não redutível aos indivíduos e controlando a sociedade por meio de leis próprias influenciou fortemente o movimento cultural na Geografia liderado em especial por Carl Sauer (DUNCAN, 2012).

Contudo, é a concepção de cultura dada pela a Nova Geografia Cultural que mais nós interessa nesse trabalho, pois ela não enxergar a cultura como uma força capaz de determinar a sociedade, mas a encara como um contexto, ou seja, como reflexo, meio e condição da existência das pessoas e dos grupos. Assim, a cultura entra em uma perspectiva interpretativa, composta de significados criados e recriados por grupos sociais refletindo as diversas esferas da vida e suas espacialidades. Concepção de cultura bem próxima a adota na Geografia humanista (CORRÊA \& ROSENDAHL, 2011, 2012b).

Para Claval (1999) a cultura é concebida segundo alguns critérios, do qual podemos mencionar alguns: mediação entre o homem e a natureza; a herança, resultado de um jogo de comunicação; permite aos indivíduos e aos grupos se projetarem no futuro; feita por palavras, articuladas por discursos e realizada na representação; fator essencial de diferenciação social. O escritor menciona ainda, a paisagem como o objeto de trabalho da geografia cultural, através da marca cultural. Apesar de não serem citadas, outras categorias como o lugar e o território, também ganham destaque nesse estudo.

Entre outras formulações nenhuma idéia de cultura poderá ser desconsiderada ou despercebida, tendo em cenário que ambas "foram feitos pelos e para os humanos e todos implicam uma ação/relação do 
homem no espaço e no tempo. O agregado dessas formulações enriquece o nosso estudo, pois as múltiplas aparências remetem e enriquecem a mesma essência" (autor, 2013, p. 124).

A cultura é a chave para a compreensão sistemática de diferenças e semelhanças entre os homens (WAGNER e MIKASSEL, 2011). Santos (2012, p. 326) a conclama como "forma de comunicação do indivíduo e do grupo com o universo, é uma herança, mas também um aprendizado das relações entre o homem e o meio". Portanto, podemos dizer que a cultura implica como o homem percebe e atua no espaço. Tuan (2012) reconhece a importância desse elemento na percepção e preferência ambiental das pessoas.

Complementando essa idéia, Mello (2005) em seu entendimento, considera que algumas manifestações culturais são ricas em relatos pessoais, ficando visíveis as experiências diretas com o seu grupo social e lugar. Ainda, segundo White e Dillingham (2009), a base da cultura é o símbolo, e esse será o próximo conceito a ser discutido.

\section{Símbolo e significado}

[...] a Terra é um texto a decifrar, que o desenho da costa, os recortes da montanha, as sinuosidade dos rios, formam os signos desse texto. O conhecimento geográfico tem por objeto esclarecer esses signos, isso que a Terra revela ao homem sobre sua condição humana e seu destino (DARDEL, 2011, p. 2)

Pode-se dizer que a discussão de símbolos e significados é um ponto nevrálgico para se compreender a dimensão e essência do conceito de lugar. Porém, é uma reflexão pouca aprofundada em Geografia e não vem despertando o valor necessário nos geógrafos para uma postulação de lugar mais sólida e coerente, exceto por Mello (2008a, 2008b).

O homem sempre está em busca de significados e ressignificações e é no espaço, horizonte vivido, que ele encontra essa possibilidade através da mobilidade (BUTTIMER, 1982). Como ressalta Relph (1976), os significados ou símbolos estarão do lado das características físicas ou aparentes e das funções concretas observáveis para descobrirmos como o lugar é construído. Dessa forma, se lança 
aqui uma breve discussão a respeito desses conceitos com intuito de fortalecer a abordagem teórica do lugar.

Segundo White \& Dillingham (2009), o homem se difere de outras espécies pela capacidade de originar, definir e atribuir significados de forma livre e arbitrária às coisas e acontecimentos externos, bem como de compreender esses significados, capacidade essa, chamada pelas autoras de capacidade de "simbologizar". As teóricas ainda definem essa habilidade como um comportamento, qual seja, de dar significado às coisas e eventos que fazem parte do cotidiano dos seres humanos.

Ainda conforme as autoras (2009), um símbolo é composto de dois elementos, o significado e a estrutura física (objeto, um ato, uma cor ou um som...). Sendo que esse último, responsável por se constituir como um veículo transmissor de significado, ou seja, entre o símbolo criado e o significado atribuído existe um objeto que materializa essa relação. Os sentidos captam apenas a estrutura física e não necessariamente o seu significado (WHITE \& DILLINGHAM, 2009). Schultz (1979) ao utilizar signo e símbolo alternadamente, assegura que, todo signo tem significado sendo, portanto, em princípio, inteligível. Para tal pensador, em geral, é absurdo falar de um signo sem significado.

Schultz (1979) aproxima-se da abordagem realizada por White \& Dillingham (2009), pois, acredita que, em uma primeira abordagem, o símbolo pode ser definido como uma referência de apresentação de ordem superior em que o membro do par que apresenta é um objeto, fato ou evento da realidade de nossa vida cotidiana. Já o outro membro par, se refere a uma idéia que transcende nossa experiência da vida cotidiana. Essa idéia pode ser considerada como um significado, termo que será melhor elucidado mais pela frente.

Sendo o lugar um espaço localizável na superfície terrestre, ou até mesmo no imaginário mediante a reconstrução de espaços efêmeros e tempos pretéritos pela memória, dotado de significado, torna-se essencial estudar o símbolo para melhor compreendê-lo. Nesse viés, consideramos sua construção como uma forma de simbologizar tendo o espaço enquanto ponto focal, sendo reconhecido por nós através do símbolo. A estrutura física nesse caso é o espaço geográfico e o significado é dado pela relação com e 
sobre ele. Logo, o homem ao ver a estrutura física ou semelhante é conduzido a relembrar o significado construído com dado meio, produzindo assim, cultura, tendo em vista que o ato de simbologizar reflete no comportamento e o comportamento influencia na forma em que o homem interfere no mundo.

Dessa forma, White e Dillingham (2009, p. 58, grifo dos autores) citando White (1959), define a cultura como "a classe de coisas e eventos que dependem da simbologização, que são produtos da simbologização". Se a cultura gira em torno e pode ser conhecida por meio dos significados construídos e estaqueados nos símbolos em um contexto que extravasa as dimensões biológicas, o lugar se constitui como uma forma geográfica de ler a cultura significativa da no espaço.

Como sustenta Corrêa (2012, p. 137) "as formas simbólicas tornam-se espaciais quando estão diretamente vinculadas ao espaço, constituindo-se fixos e fluxos". Ainda para o geógrafo, o sentido simbólico de um lugar, pode ser construído tanto por moradores quanto por não moradores, que se constitui em um complexo processo de criação e recriação, interno ou externo, no qual envolve várias tensões, sujeitos criadores e usuários de significados. Essa força simbólica possui sua lógica ligada dos significados socialmente construídos e integrados à vida do grupo social em que a construiu (CORRÊA, 2012, p. 137).

Falamos muito em símbolo, mas afinal o que é significado? O que isso representa? Para tais reflexões recorremos à contribuição de dois autores, Corrêa (2012) e Schultz (1979). Segundo Corrêa (2012, p. 134) os significados "são construções intelectuais que visam dar sentido às esferas da vida". Esse intelectual tendo como base Cassirer (2001), confere que compreender os significados criados por nós e pelos outros se constitui em uma forma de construir um conhecimento mais profundo de um dado aspecto da realidade, além do conhecimento de sua organização, constituição e estrutura.

Segundo Schultz (1979):

[...] Somente o que já foi vivenciado é significativo, e não aquilo que está sendo vivenciado. Pois o significado é meramente uma operação de intencionalidade, a qual, no entanto, só se torna visível reflexivamente. Do ponto de vista da experiência que está se passando, a predicação de significado é, necessariamente, trivial, já que significado, aqui, só pode ser entendido como um olhar atento dirigido não à experiência que está passando, mas à experiência já passada (SCHULTZ, 1979, p.63). 
Visto isso, o estudioso entende o significado com algo vivenciado e, sobretudo, refletido. Ainda, como sustenta Tuan (2012, p. 203) "os significados emergem das experiências mais profundas que se acumulam através do tempo". Complementando, Mello (2008a, p. 167) assegura que os "lugares e símbolos adquirem profundo significado, através dos laços emocionais tecidos ao longo dos anos".

Corrêa (2012) pensando a respeito, e tendo as leituras de Hall (1997) como ponto de reflexão, acredita que os significados devem ser vistos em uma perspectiva construtivista, resultantes de uma elaboração ancorada na experiência dos vários grupos sociais envolvidos. De tal modo, o geógrafo os considera instáveis e caracterizados por polivocalidade, tendo em vista, que cada grupo poderá construir significados distintos para os mesmos processos e fenômenos.

Ainda para Corrêa (2012), os significados, criados e recriados pelos diversos grupos sociais, anunciam-se em símbolos ou formas simbólicas que constituem traços fundamentais do ser humano, e por sinal essas formas acabam também instituindo novos significados. Dessa maneira, podemos dizer que "um símbolo é um repositório de significados" (TUAN, 2012, p.203).

Como reverbera Schultz (1979), o mundo social no qual o homem nasce e deve procurar o seu caminho é por ele vivenciado e experiência do como uma fina rede de signos e símbolos com estrutura semântica particular de relacionamentos sociais, de sistemas de status, prestígio... Desse modo, é nesse emaranhado de relações que existem espaços latentes para a construção e reconstrução dos símbolos e significados.

Para White \& Dillingham (2009, p. 31-32) "o homem pode criar e atribuir a algo qualquer significado ou valor que queira". Continuando, Eliade (1992, p. 8-9) insere que "o símbolo revela certos aspectos da realidade - os mais profundos - que desafiam qualquer outro meio de conhecimento. [...] Seu estudo permite melhor conhecer o homem, 'o homem simplesmente', aquele que ainda não se compôs com as condições da história". 
Jaspers (1932), citado por Schultz (1979), confia que o símbolo não pode ser interpretado, exceto, por meio de outros, de modo que, a compreensão de um símbolo não consiste em captar apenas a sua significação racional, mas em vivenciá-lo existencialmente na intenção simbólica. Dessa forma, o estudo do mundo vivido, da experiência, do corpo e além dos grupos sociais, é de extrema importante para a compreensão da simbologização estabelecida entre homens e espaço.

\section{Grupos sociais}

Nesse tópico discutiremos a respeito dos grupos sociais, afinal somos seres sociais, que necessitam manter relações sociais em um mundo construído e mantido socialmente. Essa discussão será entorno do pensamento de Schultz (1979), que fomenta um tratamento especial a esse tema em sua obra.

Por ser um animal social dependente das relações afetivas que estabelece, o ser humano tolera e aprecia a proximidade. Segundo Schultz (1979) apesar do exposto, a tolerância varia intensamente de uma cultura para outra. Por essa razão, o significado subjetivo que o grupo tem para/com seus membros baseia-se em seu conhecimento de uma situação comum e, interagindo com ela, de um sistema compartilhado de tipificações e relevância. Assim, o sistema de tipificações e relevâncias compartilhado com outros membros é quem acaba construindo esse significado por meio de uma história na qual os membros participam das biografias individuais, definem os papéis sociais, as posições e o status de cada um (SCHULTZ, 1979).

Nota-se que todo individuo é membro de numerosos grupos sociais. Para Simmel, citado por Schultz (1979), esse valor será maior quando mais diferenciada a personalidade do sujeito. O autor entende a formação de um grupo como um processo no quais diversos indivíduos unem parte de suas personalidades, enquanto o que cada personalidade realmente é (uma personalidade única é concisamente aquilo que não pode ser repartido com outros) fica de fora dessa área comum.

Logo, para o intelectual, os grupos são caracteristicamente diferentes uns dos outros, devido às personalidades totais dos membros e às partes de suas personalidades que compartilha com o mesmo. 
Nessa conjuntura, o indivíduo enquanto situação particular se vê emaranhado de vários papéis sociais, que são vivenciados conforme um conjunto de tipificações, que por sua vez, são ordenados segundo uma hierarquia privada de domínios de relevância, sendo essa reavaliada continuamente. É certa, que essa hierarquia não seja a mesma nos grupos sociais, talvez renegada ou vista como irrelevante pelo coletivo. Tal situação induz a conflitos de personalidade, levando assim, a redefinição ou a própria manutenção da personalidade, da forma que, o individuo possui a liberdade de escolha sobre a parte de sua personalidade que deseja compartilhar com o grupo e a hierarquia do qual a sua participação tem em cada grupo escolhido (SCHULTZ, 1979).

De acordo com De Paula (2010, p. 49), existem estruturas de significados que condizem com a de vários indivíduos, isso permite que o mundo não seja apenas o "mundo-para-mim", mas também "mundo-para-os-outros", esta coincidência de significados se define como intersubjetividade. Apesar de existirem coincidência, Tuan (2012, p.21) vai afirma que "duas pessoas não vêem a mesma realidade. Nem dois grupos sociais fazem exatamente a mesma avaliação do meio ambiente. A própria visão científica está ligada à cultura".

Certamente a dificuldade que envolve várias pesquisas que lançam mão em compreender um grupo específico, é que, possivelmente, a sua interpretação por um estranho (pesquisador) nunca coincidirá plenamente com a auto-interpretação do grupo interno, como nos alerta Schultz (1979). Destarte, encontramos situações que não foram relevadas pelo pesquisador e que são relevantes do ponto de vista interno, talvez se faça homogeneização de pessoas e pensamentos que não sejam, exatamente, correspondentes com a realidade de cada indivíduo.

Dessa forma, não podemos arriscar em generalizar para não causar uma auto-renegação e nãoconhecimento dos próprios indivíduos os quais nos lançamos a observar. Acreditamos que o método fenomenológico contribui para que esses fatos sejam minimizados no processo de pesquisa, e a compreensão do mundo de vida, ou como denominado na geografia, mundo vivido, torna-se importante para essa reflexão. 


\section{Mundo vivido e cotidiano}

Neste momento pretendemos discutir conceitos e um modo de fazer a pesquisa - o cotidiano e mundo vivido. Mundo vivido e espaço vivido, assim como, cotidiano e vida diária são vistos aqui como sinônimos com a mesma essência. Portanto foram trabalhados juntos.

De acordo com Buttimer (1982) o "mundo" deve ser entendido como um contexto no qual a consciência encontra as condições para ser revelada. Essa revelação se dá no mundo prático, ao retorno de um passado, a procura de desvendar um horizonte compartilhado e até mesmo individual. Assim, o mundo vivido se permite em uma atitude natural que certamente poderá ser avaliada por uma atitude fenomenológica e transcendental. "[...] a noção de mundo vivido sugere essencialmente as dimensões pré-reflexivas e tomadas como certas, da experiência, os significados não questionados e determinantes do comportamento" (BUTTIMER, 1982, p.172).

A geógrafa, indaga que o mundo e o meio ambiente têm sidos interpretados como meio no qual os sujeitos criam seus projetos de vida, se aloca acontecimentos e fatos, um mundo passivo, entretanto, alerta que nós geógrafos temos que estar conscientes do papel ativo do meio tanto físico como cultural na formação da experiência.

Tuan (2012) defende que o estilo de vida de um povo constitui da soma de suas atividades econômicas, sociais e ultraterrenas, gerando padrões espaciais. A melhor forma de compreendermos tal efeito é através do seu mundo vivido. Para Buttimer (1982, p. 185) "o mundo vivido, na perspectiva geográfica, poderia ser considerado como o substrato latente da experiência", qual seja, constitui-se em um fenômeno essencial por vezes escondido na experiência, mas que se mostra aflorante à medida que se pretende estudá-lo.

Schultz (1979) sustenta que:

\footnotetext{
"O mundo da vida cotidiana" significará o mundo intersubjetivo que existia muito antes do nosso nascimento, vivenciado e interpretado por outros, nossos predecessores, como um mundo organizado. Ele agora se dá à nossa experiência e interpretação. Toda interpretação desse mundo se baseia num estoque de experiências anteriores dele, as nossas próprias experiências e aquelas que nos são transmitidas por nossos pais e professores, as quais, na forma de "conhecimento à mão", funcionam como um código de referência (SCHULTZ, 1979, p. 72).
} 
Assim, se entende que mundo da vida cotidiana é construído no dia a dia. Os seres humanos aprenderam, por meio da experiência e dos conhecimentos repassados, que temos uma data para chegar e uma data para sair. Nascemos em um mundo que está sobreposto em ritmos temporais e espaciais construídos e em construção, e também com ciclos de vida humanos diferenciados sobrepostos sobre esses ritmos. Logo não participamos da construção de todos eles em sua plenitude até mesmo porque estão dados, embora não estejam acabados. De tal forma, toda a interpretação que temos desse mundo se baseia em um estoque de experiências anteriores a ele, agregados em diversos ciclos de vida humanas, repassados e ensinados para melhor se completar o ciclo de cada um (SCHUTZ, 1979).

A vida cotidiana é sempre mundo vivido e explorado por meio da experiência. Para Heller (1972), é a vida de todo o homem; e a vida do homem inteiro. Todos vivem, sem nenhuma exceção, qualquer que seja seu posto na divisão do trabalho. Para a pensadora, é nela que o homem participa com todos os aspectos de sua individualidade e personalidade, colocando em funcionamento todos os seus sentidos, capacidades intelectuais, habilidades, sentimentos, paixões, idéias e ideologias.

"A vida cotidiana não está 'fora' da história, mas no 'centro' do acontecer histórico: é a verdadeira 'essência' da substância social" (HELLER, 1972, p. 20). A vida cotidiana está carregada de alternativas, de escolhas - moralmente influenciadas ou não -, de espontaneidade - apesar de nem toda a vida cotidiana ser espontânea -, de imitação, economicismo, juízo, ultrageneralização, mímese e entonação, andologia, pragmatismo, precedentes... Portanto, o homem atua sobre a base da probabilidade, da possibilidade sendo impossível, na vida cotidiana, prever com segurança científica a consequência provável de uma ação (HELLER, 1972).

Essa dimensão da vida caracteriza-se, em última análise, pela complexidade na simplicidade do fazer acontecer da vida dos homens. "O mundo diário [...] apresenta-se em unidade dinâmica e é experiencia do de maneira holística, até que o pensamento comece a refletir sobre ele" (BUTTIMER, 1982, p.171). Trata-se do espaço como meio da vida humana, de forma que "cada modificação 'no' homem condiciona uma mudança de seu espaço vivido" (BOLLNOW, 2008, p.18). 
As relações do homem com o espaço, não podem ser considerados como imanentes ou inatos. Elas se entrelaçam em uma experiência vivida e com o tempo vivido, se constrói, se destrói e reconstrói, tratase de uma experiência contínua, um espaço-movimento e um espaço-tempo vivido. Por natureza, é egocêntrico, centrado no ego, no corpo, mas também é social, se delineando como tal em um meio povoado que se forma da infância à velhice (FREMÓNT, 1980).

Mundo vivido e lugar são conceitos que andam juntos. 0 mundo vivido visto sob a perspectiva do lugar poderia se entendido com uma tensão de forças estabilizantes e inovadoras, para ser reveladas necessita-se de uma nova tensão, o que pode mostrar alguma desarmonia entre a pessoa e o mundo (BUTTIMER, 1982).

Holzer (2012) ao tentar compreender como o sentido de mundo vivido se estabelece para a geografia em uma perspectiva fenomenológica, afirma que essa relação se dá a partir do corpo humano, o corpode-um-sujeito, o corpo que é o próprio sujeito-como-cogito.

Dessa forma, consideramos o mundo vivido como contexto que o lugar é latente, meio no qual ele se revela aos olhos de quem queira identificá-lo. Constitui-se, portanto, em um mundo complexo em sua coletividade e em sua individualidade, um espaço de sujeitos, histórias e materialidades de tempos difusos, em um meio que apenas não recebe significados, mas também significa o homem. Esse mundo, certamente, não escapa ao homem de posse, da ciência, "dos comuns". Mesmo não o pensando, se vive e se faz refletir em todas as escalas do mundo social e socializado. Não podemos negar que o conhecemos por meio da experiência, próximo assunto a ser discutido.

\section{Experiência}

O lugar se faz por meio da adoção de significado no espaço, para isso recorre ao mundo vivido e ao cotidiano para traçar essa relação. A ação dessa relação remete-nos a discutir a experiência. Não se é possível construir o lugar sem experienciá-lo, apesar de a experiência independer do lugar, o lugar depende da experiência para se fundar. Assim, procuramos discutir brevemente esse conceito. 
Para Tuan (2013, p. 18) "a experiência tem uma conotação de passividade; a palavra sugere o que uma pessoa tem suportado ou sofrido. Assim a experiência implica a capacidade de aprender a partir da própria vivência". Desse modo, subentende-se que, muitas vezes podemos escolher o que queremos experienciar, mas não escolher em ficar sem experiência. No mesmo sentido não se pode escolher em respirar ou não. Portanto, estamos experienciando do início ao fim de nossas vidas. A mesma, além de possibilitar a aquisição de capacidades permite a contextualização dos conhecimentos, nos ajudando a viver, pois "experienciar é vencer os perigos" (TUAN, 2013, p. 18).

Os sentidos aguçam a noção de espaço, a visão é o que mais colabora com esse conhecimento. Para quem não a possui, a audição se torna protagonista. "O espaço é experienciado quando há lugar para se mover" (p.13). A partir de um lugar nos projetamos para outros, para esta projeção é inevitável não depararmos com o espaço, com o processo, com o movimento. Nessa trajetória cada indivíduo decide arriscar ou resignar, e nesse momento, cada um toma como seu as concepções de distâncias e limites. De tal forma, a experiência é um termo que abrange diversas maneiras que contribui para a pessoa conhecer e construir a sua realidade (TUAN, 2013).

Merleau-Ponty (2011,p. 3) sustenta que a "[...] minha experiência não provém de meus antecedentes, de meu ambiente físico e social, ela caminha em direção a eles e os sustenta, pois sou eu quem faz ser para mim (e, portanto ser no único sentido que a palavra possa ter para mim)", seja assim, a experiência não é um repositório onde se guarda antecedentes do meio físico e social, é construída, pois "sou eu" que a faz para mim, portanto, não é um repositório, mas acaba indo ao encontro a eles e os sustentam.

Para Schultz (1979, p. 177) "[...] cada experiência é única, e até a recorrência da mesma experiência é única, e até a recorrência da mesma experiência não é a mesma, porque é recorrência". Tendo em vista essa afirmação, fica claro a complexidade e ao mesmo tempo simplicidade em estudá-la. Complexo por sua particularidade em seu cada acontecer, e simples por não recorrer a outras experiências, pois isso geraria uma nova. 
Refletindo sobre a consciência da experiência, o intelectual considera que:

\begin{abstract}
O que nós de fato vivenciamos na "duração" não é uma coisa delimitada e bem definida, mas uma transição constante de um 'agora-assim' para outro 'agora-assim'. Dessa forma, a consciência da experiência na corrente de duração pura é transformada a cada momento em lembrança do que acaba de ter sido assim; é o lembrar que suspende a experiência da corrente de duração irreversível e modifica, assim, a consciência, transformando-a em lembrança (SCHULTZ, 1979, p. 61-62).
\end{abstract}

O que nos faz voltar a refletir a experiência como única, apesar de se repetir em sua factualidade, nunca é a mesma, sempre é outra. Assim, vivemos uma constante passagem de um "agora-assim" para outro "agora-assim". De forma que esse é transformado em lembrança do que acabou de acontecer. Schultz (1979) ainda destaca que, a avaliação da experiência do fenômeno deve ser de alguém que se comportou e nunca de alguém se comportando.

Lowenthal (1982) nos dá por certo, que todos os tipos de experiências, incluindo aquelas que parecem distantes, contribuem para compor o nosso quadro individual da realidade. Ela é única, mas não somente, é também autocentralizadora, isto é, reconheço enquanto parte do seu meio ambiente, mas não do meu, isso reflete que nunca me vejo como o mundo me vê. Para o humanista, o que deixa mais complexo essa relação é o fato que cada visão particular do mundo ser única, deste modo, cada um escolhe e reage diferentemente ao meio.

"O mundo da experiência humana é, então, apenas uma árvore da floresta. A diferença é que o homem sabe que a sua árvore não é única, e pode imaginar que a floresta, como um todo, possa ser semelhante" (LOWENTHAL, 1982, p. 166). Assim, reconheço a minha experiência como única, mas não isolada, quando visualizo que existe uma floresta de experiências, compreendo que posso compartilhar com outras árvores a semelhança.

Apesar de serem sinônimos, vivência e experiência remetem significados diferentes. Como assegura De Paula (2010), enquanto vivência expressa nossa interação como o mundo, a experiência remete o conhecimento intuitivo gerado por esta interação. Os elos entre os dois formam o conhecimento experiencial. "É na vivência que os fenômenos surgem; e é a partir da experiência que a produção científica pode acercar sua construção" (DE PAULA, 2010, p. 48). 
Marandola Jr. (2005) decorre que no estudo de experiência envolvem-se os sentidos, as sensações, percepções e algumas relações entre diversos polos tanto complementares quanto concorrentes (Tempo-espaço, subjetividade-objetividade, história-memória, indivíduo-sociedade). É interessante também, que o autor invoca para o estudo da experiência o estudo da existência, dando um caráter filosófico. Todas as noções evocadas pela experiência envolvem o corpo, assim sendo, trataremos explorá-lo.

\section{Corpo}

Trataremos agora do corpo, o primeiro espaço que o homem ocupa antes do espaço propriamente dito. O corpo nesse intuito media a relação do ser com o meio ambiente, e depende de suas condições para que o sujeito melhor enfrente as mazelas da vida. Pensadores como Bollnow (2008), Buttimer (1982), Chaveiro (2012), Fremónt (1980), Merleau-Ponty (2011) e Tuan (2013, 2014) vão nos ajudar a compreender o corpo e a sua relação com o espaço.

O corpo para o ser humano é aquela parte do universo material que se conhece mais intimamente, é uma condição para experienciar o mundo, mas, sobretudo, é um objeto acessível cujas propriedades podemos sempre observar. O mesmo está impregnado de valores, resultado de tensão das funções fisiológicas com o mundo, de tal maneira, carrega emoção e experiências íntimas (TUAN, 2013).

Ainda para a autoridade (2014), os seres humanos são corpo e mente. Falar de corpo é falar de sentidos, uma vez que, por meio desses fazemos o contato com o ambiente, logo, a relação temporal trata de significar essa relação, construindo lugar. Já a mente não se evade ao lugar que a circunda, mas se expande na dimensão de outros mundos. Tuan (2014) ao fazer analogia do corpo e mente com o lugar e o espaço, considera o corpo como lugar e a mente como o espaço.

"O corpo transporta e concentra todas as rugosidades do espaço que o envolve" (FREMÓNT, 1980, p. 49). Como destaca Tuan (2013, p. 49), "o corpo é uma 'coisa' e está no espaço ou ocupa espaço". Tendo em vista o assunto, Bollnow (2008) o trata de acordo com duas funções. Primeiro, o corpo por 
meio dos sentidos e a sua capacidade de movimento se torna a ferramenta com cujo auxílio nos é dado o espaço. E segundo, o corpo é ele mesmo um espaço, se tornando a sede do meu eu, portanto, pertence ao objeto vivenciado.

Conforme menciona Chaveiro (2012), o espaço e seus componentes são essenciais na existência do corpo e da vida que o recobre, de tal modo, não é possível sem a experiência do corpo haver existência do espaço, de suas categorias e de outro atributo que permita a ação humana. Corpo e espaço são conceitos diferentes, mas inseparáveis, não me é possível pensar e viver o corpo sem espaço, consoante a isso, não é possível pensar e viver o espaço sem a relação e tensão da experiência do corpo sobre esse.

O corpo, como um todo, ganha significativo papel para a compreensão da espacialidade humana, visto que é "por meio do meu corpo que eu sou admitido no mundo espacial" (BOLLNOW, 2008, p. 305). "[...] o corpo, retirando-se do mundo objetivo, arrastará os fios intencionais que o ligam ao seu ambiente e finalmente revelará o sujeito que percebe assim como o mundo percebido" (MERLEAUPONTY, 2011, p. 110).

Como atesta Merleau-Ponty (2011) à ação é o movimento que a espacialidade do corpo se realiza. Para o filósofo, o que menos importa é o corpo enquanto coisa no espaço objetivo, mas ele enquanto sistema de ações possíveis, um objeto virtual cujo espaço fenomenal é definido por sua tarefa e por sua situação.

Caso fossemos focalizar o relacionamento entre corpo e mundo, iríamos levantar diversas questões filosóficas e metodológicas. Considerar o comportamento do corpo fora de um meio torna-se "ininteligível". Porém enxergá-lo apenas como um meio ambiente em si mesmo, pouco contribuiria para revelar os conteúdos da experiência. Já considerá-lo como um objeto, deixaríamos de reconhecer a importância da psique. Cabe encontrar um ponto de equilíbrio entre essas formas de ver o corpo, o corpo está mais para a ação do que para a própria produção de conhecimento (BUTTIMER, 1982, p. $176)$. 
"Não podemos conhecer inteiramente o corpo, exceto através da vida que vivemos dentro dele, no mundo. [...] Os procedimentos científicos falham em prover descrições adequadas da experiência" (BUTTIMER, 1982, p. 176), ou seja, esses procedimentos pecam por separar corpo e mente em suas análises, sendo assim, a melhor forma de se ver o corpo, é enxergá-lo enquanto ação e vida que vivemos dentro dele.

Como salienta Chaveiro (2012):

[...] O corpo é a propriedade pela qual o sujeito pode fundar a sua extrema singularidade, registrar na carne a sua história na linha de contato e de intersecção com a história do mundo e dos lugares, mote para experimentar a si mesmo, peça de sentido para colher a propriedade das coisas e para afetá-las com a percepção e com a ação, recurso de entranhamento no tempo e de realização temporal no encontro com o outro, figura de interferência, de gozo - e de descoberta (CHAVEIRO, 2012, p. 250).

O corpo, assim, corresponde em uma maneira de mostrar a sua identidade construída através de sua historia no mundo e com ele, igualmente, uma forma de tensionar o seu ser enquanto ser-no-mundo e com o outro.

Em relação ao lugar, Chaveiro (2012) considera que "o corpo, é de fato, um guardador de lugares" (p. 253) e "o lugar: um guardador de relações corporais" (p. 254). Nesse sentido, o pesquisador indaga que todo corpo ocupa e vive lugares, e acabam também, sendo o registro de trajetórias experienciadas por onde passou e se quis passar. "O corpo como estatuto da existência, em diagramas sociais, torna-se corporeidade que sofre representações" (CHAVEIRO, 2012, p. 277). O lugar por certo, guarda e resguarda o movimento do corpo materializado em sua estrutura física e simbólica. O corpo exige proteção, sustentação afetiva e moral, para isso, recorreremos a discutir o sentido de lar e casa.

\section{Lar}

"Não há lugar como o lar" (TUAN, 2013, p. 11). 
O lar ganha importância nesse estudo, tendo em vista que é um lugar concentrado de valores incomparáveis com os demais, é um lugar inigualável para a existência humana, portanto, "um centro de significados insubstituível" (RELPH, 1976, p.39). Quem não o possui o procura, "a ausência de lar pode nos levar à saudade" (RELPH, 2012, p. 24).

O que, entretanto, deve ser estendido por "lar"? "Lar é de onde se parte", diz o poeta. "Lar é o lugar para onde o homem tem intenção de retornar quando está longe" diz o jurista. "O lar é o ponto de partida como ponto terminal". É o ponto zero do sistema de coordenadas que atribuímos ao mundo a fim de nos movimentar dentro dele. Geograficamente, "lar" significa um certo local na superfície da Terra. Onde por acaso eu me encontro é o meu "domicílio"; onde tenho intenção de ficar é a minha "residência"; de onde venho e para onde quero retornar é o meu "lar". No entanto, lar não é apenas o local - minha casa, meu quarto, meu jardim, minha cidade - mas tudo o que ele simboliza. O caráter simbólico da noção de "lar" é emocionalmente evocativo e difícil de descrever. Lar significa coisas diferentes para pessoas diferentes. Significa, é claro, a casa paterna, a língua materna, a família, o amor, os amigos; significa uma paisagem querida, "canções que minha mãe ensinou", comida preparada de um determinado modo, coisas familiares para uso diário, costumes, hábitos pessoais - em suma, um estilo peculiar de vida, composto de pequenos elementos importantes e queridos (SCHULTZ, 1979, p. 291).

O lar é identificado como centro, como ponto de referência, o local para onde se deseja ir quando está longe, com saudades, aonde se vai e se volta. Ele pode ser identificado em sua objetividade enquanto domicílio, residência, casa. Entretanto, não se restringe em sua materialidade física, o mesmo deve ser entendido, também, enquanto construção subjetiva e simbólica, de caráter multifacetado, "emocionalmente evocativo e difícil de descrever". O lar significa aquilo que o indivíduo o significou por meio de seus gostos, experiências e visões de mundo, construídas através do tempo e do espaço vivido.

Tuan (2013) sustenta que o lugar é uma classe especial do objeto, uma concentração de valor. O lar é um exemplo maior de lugar, e visto como especial e concentra valor para os indivíduos que ali o construíram, acrescenta o pensador. O lugar está nós olhos de quem o ver, o que tem valor para mim, não pode conter significado algum para o outro, pode ser feio, todavia, não o vejo como feiúra.

Segundo Mello (2011) em seu sentido claustrofílico, o lar consolida-se como um lugar central por natureza, se caracteriza como um refúgio íntimo de afinidade e significância, impregnado de experiências passadas e presente, em última análise, por constitui-se em um local emissor e receptor de idéias, trabalho, divertimento, sem contar o seu papel de moradia. "O lar é onde a vida começa e 
termina, $[\ldots .$.$] vamos a todos os tipos de lugares, [....] mas sempre retornamos ao lar" (LEITE, 1998,$ p.11-12).

Segundo Relph (2012) o lar é o onde pertencemos; onde o enraizamento é maior e mais forte e, também, o onde se conhece e se é conhecido pelos outros. A partir da perspectiva da experiência, se constitui um centro do mundo, pois torna-se padrão de julgamentos dos lugares, "o que é captado nos inúmeros sentimentos populares: 'Não há lugar como o lar', 'Lar doce lar', 'Lar é onde está meu coração'" (RELPH, 2012, p. 24).

O lar é para o animal o lugar onde descansa e dorme, relação bem próxima encontrada entre o homem e a sua cama. A segurança e o silêncio, quando os desejamos, reconstitui o lar, como um lugar onde se pode morar, descansar e dormir, o mesmo é reconhecido, principalmente, pela capacidade de abrigo (BOLLNOW, 2008). O conceito de casa é bem próximo ao de lar, entretanto, foi mais bem focalizado a seguir.

\section{Casa}

[...] a casa abriga o devaneio, a casa protege o sonhador, a casa nos permite sonhar em paz (BACHELARD, 1978, p. 201)

A Casa quando tratamos de lar ganhou um sentido objetivo material. Porém, a mesma possui um sentido subjetivo e são esses dois sentidos que desejamos observar nesse momento. Para a construção dessa teorização utilizamos, basicamente, o pensamento de grandes nomes como Bachelard (1978), Bollnow (2008) e Fremónt (1980).

Goyen apud Bachelard (1978) relata que:

Pensar que possamos vir ao mundo num lugar que a princípio não saberíamos nem mesmo nomear, que vejamos pela primeira vez, e que, nesse lugar anônimo, desconhecido, possamos crescer, andar até que conheçamos seu nome, pronunciando-o com amor, que o chamemos de lar, em que afundemos nossas raízes, onde abriguemos nossos amores, ainda que, cada vez que falarmos dele, o façamos como se fôssemos amantes, em cantos de nostalgia, em poemas transbordantes de desejo (GOYEN apud BACHELARD, 1978, p. 234). 
Como se percebe, o lar existe antes mesmo de imaginarmos a sua existência concreta e de o pronunciarmos. Um dos sinônimos de lar é a casa. Bachelard (1978) explora bem essa questão, para o filósofo a casa por si só, já é um mundo, um universo que ao mesmo tempo pode ser miniatura ou a própria imensidão desse universo. A partir do pensador comparamos a casa e o lar com o ninho e a concha, notoriamente, com sentido de abrigo e aconchego.

Bollnow (2008) reverbera que o homem é encarnado em sua casa, tornando-se a mesma, expressão de sua essência. Logo, o autor acredita que esse espaço possa ser compreendido pelo caráter de personalidade que o homem imprime em sua habitação, remete, a relação íntima entre homem e espaço, esboça a idéia de encarnação.

Ao relacionar esse fato com o papel de proteção, apresentamos o trecho a seguir:

\begin{abstract}
A casa lutava bravamente. Em lamentos, a princípio; as piores rajadas a atacavam de todos os lados ao mesmo tempo, com um ódio distinto e tais urro de raiva que, durante alguns momentos, eu tremia de medo. Mas ela resistiu. Desde o início da tempestade, ventos violentos arrancaram parte do telhado. Tentaram arrancá-la, partir-lhe os rins, transformá-la em destroços, aspirá-la. Mas ela curvou o dorso e segurou-se firme à velha trave-mestra. Outros ventos vieram e, enfiando-se pelo rés-do-chão, se atiraram contra as paredes. Tudo se vergou ao choque impetuoso, mas a casa, flexível, tendo-se curvado, resistiu à fera. Sem dúvida, ela se prendia ao solo da ilha por raízes inquebrantáveis, daí porque suas paredes finas de pau-a-pique e de madeira tinham uma força que se afigurava sobrenatural. Em vão atacaram suas janelas e suas portas, fizeram ameaças colossais, clarearam a chaminé, o ser ora humano, em que eu abrigava meu corpo, não cedeu nada à tempestade. A casa se apurou contra mim, como uma loba, e por momentos senti seu cheiro descer maternalmente até o coração. Ela foi realmente a minha mãe, naquela noite (LA REDOUSSSE, s. d, p. 115, apud BACHELARD, 1978, p. 226).
\end{abstract}

A casa encarna, nesse sentido, os asseios do homem que sofre e sente como se fosse o seu corpo ou sua armadura, a tormenta de um mundo exterior que se transforma em um ambiente temido e até mesmo ameaçador. A casa fica firme e o protege como se fosse a sua mãe, como se atendesse anseios de um corpo que por si só não tem as forças para enfrentar a tormenta, essa proteção sela ainda mais a relação de confiança e intimidade do homem com a casa.

No que concerne a tal texto, Bachelard (1978, p. 227) reforça que "a casa toma as energias físicas e morais de um corpo humano. Ela se curva a chuvarada, mas se torna inflexível. Sob rajadas ela se 
encolhe quando é preciso encolher, segura de se estirar de novo e de negar sempre as derrotas passageiras". Nessa passagem pode-se dizer que a casa é um lugar de intercessão quase mágica entre os seus habitantes e o mundo (FREMÓNT, 1980).

Deffontaines, citado por Fremónt (1980), considera a casa como uma adaptação às necessidades do homem - o criador de seu próprio meio de vida-, uma marca essencialmente humana. Para Deffontaines é provavelmente cada vez mais difícil encontrar casos de homens que não se fixam, pelo menos temporariamente ou sumariamente.

Eliade citado por Bollnow (2008) afirma que para poder viver no mundo, deve-se fundá-lo, e a casa se manifesta na melhor forma disso. O homem necessita de um centro no qual ele esteja enraizado no espaço e que todas as relações espaciais se refiram a ele. A casa, nesse sentido, ganha status de território santificado. 0 que dizer de uma pessoa que entra sem permissão na sua casa ou até mesmo em seu quarto? (BOLLNOW, 2008).

Nesse diapasão, o espaço se vê dividido em dois âmbitos: um espaço especial, nitidamente delimitado pelos muros ou paredes da casa, portanto privado; e um espaço grande, aberto, se distinguindo do espaço interno por sua exterioridade (BOLLNOW, 2008).

Assim entendemos a casa como um lugar íntimo, pois "os lugares íntimos são lugares onde encontramos carinho, onde nossas necessidades fundamentais são consideradas e merecem atenção sem espalhafato" (TUAN, 2013, p. 168). Um exemplo mencionado pelo autor, é a cidade natal, que pode ser simples, "não importa sua feiúra" (TUAN, 2013, p. 177), quando um estranho faz uma crítica, acabamos nos ofendendo, pois a cidade, o bairro, a rua e a casa enquanto objetos simbólicos fazem parte de nossa identidade. Para Bachelard (1978, p. 200) "até a mais modesta habitação, vista intimamente, é bela". Ao reconhecermos que o nosso quarto é mais íntimo do que outros lugares, um mínimo de privacidade é uma necessidade fundamental (TUAN, 2012). 
"Para um estudo fenomenológico da intimidade do espaço interior, a casa é, evidentemente, um ser privilegiado" (BACHELARD, 1978, p.199). Desse modo, para o autor, o fenomenólogo deve-se considerar ainda a sua unidade e complexidade, esforçando-se para compreender o germe da felicidade central, seguro e imediato. Ainda segundo Bachelard (1978, p. 201), "é necessário mostrar que a casa é um dos maiores poderes de integração para os pensamentos, as lembranças e os sonhos do homem", "ela é corpo e alma", "[...] é um grande berço", "a vida começa bem; começa fechada, protegida, agasalhada no seio da casa", ela é "um ninho no mundo" (p. 264).

Estudar a casa é um esforço de dizermos como habitar nosso espaço vital de acordo com as dialéticas da vida, como se tange o enraizamento no cotidiano nesse espaço que pode ser considerado como "canto do mundo", "um verdadeiro cosmos" (BACHELARD, 1978, p. 200). Estudar a casa nos remete também aos valores de abrigo, que por seu profundo enraizamento no inconsciente, pode ser encontrados a partir de uma simples evocação em vez de uma descrição minuciosa (BACHELARD, 1978).

Vale refletir que, todo espaço verdadeiramente habitado traz a essência da noção de casa, assim toda a forma de habitação resguarda valores de onirismo consoante (BACHELARD, 1978). ParaBachelard (1978) lembrança da casa de infância o faz reviver momentos únicos, ouvir lembranças de pessoas próximas, o faz identificar o "[...] ser que domina os lugares de suas lembranças mais valorizadas" (p. 206). Dessa maneira "[...] a casa da lembrança se torna psicologicamente complexa [...], a casa natal é uma casa habitada. [....] Mas, além das lembranças, a casa natal está fisicamente inscrita em nós. Ela é um grupo de hábitos orgânicos" (BACHELARD, 1978, p. 206).

\footnotetext{
Mesmo que nós não queiramos, artificialmente, exagerar na analogia, podemos considerar a casa de certo modo um corpo expandido, com que o homem se identifica de modo semelhante e pelo qual ele, correspondentemente, se classifica num espaço circundante maior. Aqui, como lá, há uma fronteira que inteligivelmente separa o espaço próprio, com quem eu me identifico, que eu num certo sentido "sou", do outro espaço, que eu não mais sou, que não me pertence e que me é estranho. Mas aqui, a diferença consiste em que eu me tornei inseparável do espaço próprio corporal, e o carrego comigo, para onde que eu vá, mas que o espaço caseiro está fixo, de modo que eu posso deixá-lo e tornar a ele (BOLLNOW, 2008, p. 309).
} 
O corpo de tal modo como a casa, assume ponto de interesses do homem, o primeiro é a casa do ser no mundo e o segundo, é a casa dessa casa (corpo) no mundo, dessa maneira podemos entendê-la como um corpo expandido. Com o primeiro posso me mover, o segundo está fixo, mas seguro de modo que posso retornar a ele. Refletindo ainda a relação da casa com o corpo, Michelet, citado por Bachelard (1978), nos sugere que a casa é construída para o corpo e pelo corpo, modelada em sua forma interior como uma concha.

Em termos mais práticos, para Tuan (2013, p. 176), "a casa como lugar está cheia de objetos comuns. Nós os conhecemos através do uso", ou seja, é conhecida através do tempo, do cotidiano, da experiência que se tem com ela, da funcionalidade que se atribui, da organização que se faz, do uso, de forma geral.

Fremónt (1980) ao discorrer sobre a casa em termos materiais considera que:

A edificação de uma casa mobiliza as competências dos técnicos da construção, dos promotoresgestores e dos arquitetos, que se consideram, com razão, ao mesmo tempo homens de técnica e de arte. Além disso, o futuro habitante pode ele próprio participar no ato de criação (FREMÓNT, 1980, p. 255).

As especializações dos homens e das técnicas afastam cada vez mais as pessoas das atividades elaboradas de sua necessidade. A edificação da casa não é diferente. A nova realidade espacial e social implica em mais uma nova configuração: dos homens que participam no ato de criação através da escolha dos profissionais que iram construir e o que vão construir; os homens sem opção que irão construir por conta própria com os materiais que conseguirem extrair ou comprar; e os que não têm espaço e nem dinheiro para construir e ficam na espera de serem contemplados pelo estado com uma casa ou um apartamento, nesse caso, não participam do processo de criação e ainda são submetidos a modelos prontos (AUTOR, 2014).

\section{A IMPORTÂNCIA DO ESTUDO DE LUGAR PARA A COMPREENSÃO DA RELAÇÃO AFETIVA DOS HOMENS COM O MEIO AMBIENTE}


A necessidade de se estudarmos o lugar decorre, primeiramente, da premência de conhecer a nós mesmos, de uma carência em compreender como são estabelecidos e entrelaçados os vínculos de pessoas ou grupos com determinado espaço. Como destaca Cosgrove (2012, p. 236), "uma geografia efetivamente humana é uma geografia humana crítica e relevante, que pode contribuir para o próprio núcleo de uma educação humanista: melhor conhecimento e compreensão de nós mesmos, dos outros e do mundo que compartilhamos".

Sabemos quando o espaço é complementado de significados particulares, esse acaba se constituindo como pertencente ao sujeito, de forma que, mesmo havendo separação física, prevalece um grande elo afetivo e subjetivo. Essa concepção consolida-se na concepção de Pocock (1981, p. 337), no qual os "lugares devem ser considerados como pessoas e pessoas como lugares". Por esse modo, os lugares são flexíveis, igualmente, como as pessoas. A perspectiva de erigir o sentido de lugar conjuga-se com o sentido da construção de amizade e familiaridade entre as pessoas.

O lugar é a melhor forma geográfica de conhecer os valores, os significados e os sentimentos edificados pelo homem no espaço. O mesmo valoriza o mundo vivido, o cotidiano, as experiências e afeições que os homens estabelecem com e no espaço. Ele não desconsidera os aspectos culturais e sua diversidade, pois sabe que o homem é um ser da cultura, para a cultura e que produz cultura. Por meio dessa, que temos um emaranhado de gostos, tradições, costumes e visões de mundo que acabam por afetar como o homem se apropria simbolicamente do espaço.

O homem é um ser social, portanto, participa de grupos sociais, que podem ser poucos ou muitos, a depender da identidade que deseja compartilhar com cada um desses, conforme a necessidade de estabelecer vínculos com outras pessoas, conforme a necessidade de se sentir pertencente, aceito, e verdadeiro por compartilhar a identidade escolhida.

O ser ocupa um espaço, e esse primeiro espaço é o corpo, a casa do homem na terra é ele. O mesmo se movimenta, estabelece relações, capta sentidos, sentimos dispostos a percorrer e explorar o mundo, não somente pelo corpo, mas decisivamente por ele para as decisões e a forma que o homem enxerga e 
se apropria do espaço. Tendo em vista, que a busca de abrigo é para atender a fraqueza do corpo perante a natureza, o lar e a casa acabam se constituindo em uma extensão do corpo, em um abrigo para o corpo e, logicamente, um abrigo para todo o universo particular que precisamos enquanto indivíduos.

Estar vivo é estar sobreposto em mosaicos de espaços e lugares. Nesse sentido transitamos de lugares a espaços em escalas temporais e espaciais, muitas vezes, imperceptíveis, a depender da intensidade de cada um. Essa destonação se reflete por haver um equilíbrio entre as forças simbólicas, no entanto, bastam instantes para que nós nos sentirmos inseguros ou postos em risco, que como uma ignição, faz inflamar as mais intensas reações. A relação de espaço e lugar é benéfica ao homem, precisamos de segurança e liberdade, a partir deles o homem, constrói o complexo sistema de significados e símbolos estabelecido entre ele e o meio em que vive, construindo assim, relações topofílicas e topofóbicas.

Perguntas como "onde?", "quando?" e "quem?" podem trazer respostas reveladoras no estudo do espaço e do lugar, pois o onde permite identificar a localização, seja concreta ou simbólica, a distribuição e a intensidade do fenômeno a ser estudado; o quando proporciona identificar a relação temporal, tais como duração, época e historia; "o quem?" nos possibilita reconhecer indivíduos ou grupos e suas relações. Apesar de serem perguntas díspares são matriciais para identificarmos as relações simbólicas, topofílicas e topofóbicas do homem com o meio.

O lugar é um centro de significados e valores, e é por meio dele, mas não somente, que podemos melhor estudar as relações afetivas e também as relações de desavenças do homem com o universo vivido.

\section{REFERÊNCIAS}

BACHELARD, Gaston. A poética do espaço. Coleção Os Pensadores. São Paulo: Abril Cultural, p. 181-354, 1978.

BERDOULAY, Vicent. Espaço e cultura. In: CASTRO, Iná Elias; GOMES, Paulo Cezar da Costa; CORRÊA, Roberto

Lobato (orgs.). Olhares Geográficos: modos de ver e viver o espaço. Rio de Janeiro: Bertrand Brasil, p. 101-131, 2012.

BOLLNOW, Otto Friedrich. O homem e o Espaço. Tradução de Aloíso Leoni Schmid. Curitiba: Editora UFPR, 2008,327 p.

CASSIRER, Ernst. A filosofia das formas simbólicas: primeira parte. A linguagem. São Paulo: Martins Fontes, 2001. 
CHAVEIRO, Eguimar Felício. Corporidade e Lugar: Elos da Produção. In: MARANDOLA JR., Eduardo; HOLZER, Werther; OLIVEIRA, Lívia de (orgs.). Qual o espaço do Lugar? Geografia, epistemologia, fenomenologia. São Paulo: Perspectiva, p. 249-279, 2012. (Estudos; 302).

CLAVAL, Paul. A Geografia Cultural. Tradução: Luiz Fugazzola Pimenta; Margareth Afeche Pimenta. Florianópolis: Ed. da UFSC, 1999, $453 \mathrm{p}$.

CORREAA, Roberto Lobato. Espaço e simbolismo. In: CASTRO, Iná Elias de; GOMES, Paulo Cesar da Costa; CORREAA, Roberto Lobato (orgs). Olhares geográficos: modos de ver e viver o espaço. Rio de Janeiro: Bertrand Brasil, p. 133-153, 2012.

COSGROVE, Denis. A geografia está em toda parte: cultura e simbolismo nas paisagens humanas. In: CORRÊA, Roberto Lobato; ROZENDAHL, Zeny (orgs.). Geografia Cultural: uma antologia (1). Rio de Janeiro: Eduerj, p. 219-237, 2012.

DARDEL, Eric. O homem e a terra: natureza da realidade geográfica; tradução Werther Holzer. - São Paulo: Perspectiva, 2011, $113 \mathrm{p}$.

DE PAULA, Fernanda Cristina. Constituições do habitar: reassentamento do Jd. São Marcos ao Jd. Real. $2010,129 \mathrm{f}$. Dissertação (Mestrado em Geografia). Pós-graduação em Geografia análise ambiental e dinâmica territorial, Instituto de Geociências, Universidade Estadual de Campinas, 2010.

DUNCAN, James S. Após a guerra civil: reconstruindo a geografia cultural como heterotopia. In CORREA A, Roberto Lobato; ROZENDAHL, Zeny (orgs.). Geografia Cultural: uma antologia (1). Rio de Janeiro: Eduerj, 2012, p. 219-237.

FREMÓNT, Armand. A região, espaço vivido. Coimbra: Almedina, 1980, 220 p.

HELLER, Agnes. O cotidiano e a história. Rio de Janeiro: Paz e Terra, 1972, 121 p.

HOLZER, Werther. A Geografia Humanista - sua Trajetória de 1950- 1990. 1992, 550 f. Dissertação (Mestrado em Geografia). Instituto de Geociências, Universidade Federal do Rio de Janeiro, 1992.

Mundo e Lugar: Ensaios de Geografia Fenomenológica. In: MARANDOLA JR., Eduardo; HOLZER, Werther (orgs). Qual o espaço do Lugar?: geografia, epistemologia, fenomenologia. São Paulo: Perspectiva, p. 281-304, 2012. (Estudos; 302).

JAPIASSÚ, Hilton; MARCONDES, Danilo. Dicionário Básico de Filosofia. Rio de Janeiro: Jorge Zahar Editor, 2001, p. 212.

LOWENTHAL, David. Geografia, Experiência e Imaginação. In: CHRISTOFOLETTI, A. (org.). Perspectivas da Geografia. São Paulo: Difel, p. 165-193, 1982.

MARANDOLA JR., Eduardo. Da existência e da experiência: origens de um pensar e de um fazer. Cadernos de Geografia, Belo Horizonte, v. 15, n. 24, p. 49-67, 2005.

. Habitar em Risco: mobilidade e vulnerabilidade na experiência metropolitana. 2008, 278 f. Tese (Doutorado em Geografia) - Instituto de Geociências, Universidade Estadual de Campinas, Campinas, 2008

MELLO, João Baptista Ferreira de. O Rio de Janeiro dos compositores da música popular brasileira - 1928/1991 - uma introdução à geografia humanística. 1991, 328 f. Dissertação (Mestrado em Geografia) - Instituto de Geociências, Universidade Federal do Rio de Janeiro, 1991.

Dos espaços da escuridão aos lugares de extrema luminosidade - o universo da estrela Marlene como palco e documento para a construção de conceitos geográficos. 2000, 224 f. Tese (Doutorado em Geografia) - Instituto de Geociências, Universidade do Estado do Rio de Janeiro, 2000. 
Valores em Geografia e o dinamismo do mundo vivido na obra de Anne Buttimer. Espaço e Cultura, Rio de Janeiro, v. 19-20, p. 48-58, 2005.

O Rio dos Símbolos Oficiais e Vernaculares. In: ROSENDAHL, Zeny; CORRÊA, Roberto Lobato. (Orgs.). Espaço e Cultura: Pluralidade Temática. Rio de Janeiro: EdUERJ, 2008, v. , p. 173-186.

Símbolos dos Lugares, dos Espaços e dos "Deslugares". Espaço e Cultura, Rio de Janeiro, v. 1, p. 167-174, 2008.

MERLEAU-PONTY, Maurice. Fenomenologia da Percepção. São Paulo: Editora WMF Martins Fontes, 2011,662 p.

POCOCK, David. Place and the novelist. Transactions of the lnstitute of British Geographers N.S., (6), p. 337-347, 1981.

RELPH, Edward. Place and placelessness. London: Pion, 1976, 156 p.

SANTOS, Milton. Por uma Geografia Nova: Da crítica da Geografia a uma Geografia Crítica. São Paulo: Edusp, 2004,285 p.

A natureza do espaço: Técnica e Tempo. Razão e Emoção. São Paulo: Edusp, 2012, 384 p.

SCHUTZ, Alfred. Fenomenologia e relações sociais. Organização e introdução de Helmut R. Wagner. Zahar: Rio de Janeiro, 1979, $319 \mathrm{p}$.

SPOSITO, Eliseu Savério. Geografia e filosofia: contribuições para o ensino do pensamento geográfico. Presidente Prudente: Unesp, 2004, 218 p.

TUAN, Yi-Fu. Espaço, tempo, lugar: um arcabouço humanista. Geograficidade, v. 01, n. 01, p. 4-15, Inverno 2011.

Topofilia: um estudo da percepção, atitudes e valores do meio ambiente. Londrina, PR: Eduel, 2012, 344 p.

Espaço e Lugar: a perspectiva da experiência. Tradução de Lívia de Oliveira. Londrina, PR: Eduel, 2013,

$248 \mathrm{p}$.

VIGOTSKI, Lev Semenovitch. A Formação Social da Mente: o desenvolvimento dos processos psicológicos superiores. São Paulo: Martins Fontes, 1989.

Pensamento e linguagem. Tradução de Jefferson Luiz Camargo; revisão técnica de José Cipolla Nelo. $4^{\mathrm{a}}$ ed. São Paulo: Martins Fontes, 2008, 194 p.

WAGNER, Philip. L.; MIKASELL, Marvin. W. Os temas de geografia cultural. In: CORRÊA, Roberto Lobato; ROSENDAHL, Zeny (Orgs.). Introdução à Geografia Cultural. Rio de Janeiro: Bertrand, p. 27-61, 2011.

WHITE, Leslie A.; DILlinghAM, Beth. O conceito de cultura. Tradução Tereza Dias Carneiro. Rio de Janeiro: Contraponto, 2009, 127 p. 